\title{
Suspected adverse reactions to veterinary drugs reported in South Africa (January 1998 - February 2001)
}

\author{
R Gehring ${ }^{\mathrm{a}}$
}

\begin{abstract}
The Veterinary Pharmacovigilance Centre received 59 reports of suspected adverse drug reactions during the period January 1998- February 2001. The number of reports received increased after the establishment of a formal procedure for recording and responding to reports. The number of reports received per species was: dogs 19 , cats 15 , cattle 7 , sheep/ goats 6 , chickens 4 , pigs 3 , horses 2 and giraffe 1 . Many different types of adverse reactions werereported, including lack of efficacy, hypersensitivity, inappropriateuse of products by non-veterinarians, known adverse effects and adverse effects encountered with extra-label use of products.
\end{abstract}

Key words: drug regulation, pharmacovigilance, suspected adverse drug reactions.

Gehring $R$ Suspected adverse reactions to veterinary drugs reported in South Africa (January 1998 - February 2001). J ournal of theSouth A frican Veterinary A ssociation (2001) 72(3): 120-126 (En.). Department of Paraclinical Sciences, Pharmacology Section, Faculty of Veterinary Science, University of Pretoria, Private Bag X04, Onderstepoort, 0110 South Africa.

\section{INTRODUCTION}

Monitoring reports of suspected adverse drug reactions has been recognised as an essential part of an adequateregulatory system to ensure the safety and efficacy of medicinal products ${ }^{26}$. Monitoring centres that collect and analyse spontane ous reports of suspected adverse drug reactions in veterinary medicine have been established in many countries throughout the world, including the USA, Canada, UK, Ireland, Australia, New Zealand and Sweden. Collated reports are regularly published by the centres to inform members of the veterinary profession of the types of adverse drug reactions that are observed in prac-

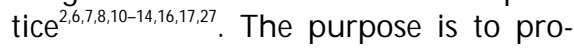
mote prudent use of medicinal products in animals and to stimulate practitioners to report suspected adverse reactions.

In South Africa, the Veterinary Pharmacovigilance Centre was established in 1998 in the Department of Pharmacology and Toxicology, Faculty of Veterinary Science, University of Pretoria. Initially, the reports were handled on an ad hoc basis within the Department. At the beginning of the year 2000, a formal system of recording, evaluating and responding to reports was developed. This included establishing the Pharmacovigilance Working Group, comprising

${ }^{2}$ Department of Paraclinical Sciences, Pharmacology Section, Faculty of Veterinary Science, University of Pretoria, Private Bag X04, Onderstepoort, 0110 South Africa.

Received: April 2001. Accepted: July 2001. the academic staff members of the Department ( 3 pharmacologists and 2 toxicologists).

A suspected adverse drug reaction can be defined as any observation in animals or humans that is harmful and unintended and occurs after the use of a medicinal product. This applies regardless of dosage when preventing, diagnosing or treating a disease or modifying physiology ${ }^{26}$.

Often, theterm adversedrug reaction is used to refer only to abnormalities that occur when a drug is administered at an appropriate dose for the intended purpose, as recommended on the package insert or label of the product ${ }^{16}$. However, the scope of adverse drug reaction monitoring extends to recording and analysing reports pertaining to extralabel use of registered human medicines in animals, herbal, homeopathic or other alternative remedies, aswell as suspected lack of efficacy of any product ${ }^{26}$. Suspected adverse reactions as a result of misuse or abuse of products or as a result of pharmaceutical defects or counterfeit products may also be reported.

There are regulatory systems worldwide that control the manufacture, use, access and supply of veterinary medicinal products $^{24}$. These regulations serve to protect the public and aim to ensure the safety of the drug to the target animal, consumer, handler of the drug and the environment, as well as the quality and efficacy of these products. Regulatory authorities assess the safety, efficacy and quality of drugs for use in veterinary medicine before registration and marketing. This assessment is based on data from pre-dinical and pre-marketing trials that are submitted to expert evaluators ${ }^{25}$. Evaluation before registration cannot ensure the safety and efficacy of a product. The relatively small sample size used in these trials means that a rare and sometimes serious reaction may not be identified. Adverse events may have multi-factorial aetiologies or are specific to a particular population. The limited period of time during which a clinical trial must be performed may be too short to discover reactions that take a long time to develop or have a delayed manifestation ${ }^{23}$.

Certain adverse reactions to a product or changes in the frequency of known adverse reactions may therefore only appear after the product has been made available for wide distribution. These adverse reactions should be recorded and analysed to provide the regulatory authorities, pharmaceutical industry, veterinary profession and general public with information that will ultimately lead to the safer and more effective use of registered medicinal products ${ }^{23}$.

Reports of suspected adverse drug reactions rarely require corrective action. Often the report is merely recorded. If a new and serious reaction is reported or there is a marked increase in the frequency of reports of a known adverse reaction, theproduct may beassigned to a priority list for surveillance, batches of the product can be withdrawn from the market or amendments to product literature can be made following discussion with the manufacturer. Amendments to the registration of the product such as limiting the use of the product to certain conditions and patients can also be made. Very rarely will the registration of the product be revoked ${ }^{9}$.

Veterinary medicinal products in South Africa are currently registered under 2 Acts and are administered by 2 separate regulatory authorities:

- The Medicines and Related Substances Control Act (Act No. 101 of 1965), administered by the National Depart- 
ment of Health. These products are called Veterinary Medicines.

- TheFertilizers, Farm Feeds, Agricultural Remedies and Stock Remedies Act (Act 36 of 1947) administered by the Department of Agriculture. These products are called Stock Remedies.

Veterinary Medicines are grouped into various schedules (unscheduled to Schedule9) based on their safety, use and habit-forming potential ${ }^{24}$. Unscheduled medicines are over the counter (OTC) productsand arelegally available directly to the public from any retail outlet. Pharmacists may supply any medicine up to Schedule 2 and Stock Remedies directly to clients for use in animals without a veterinary prescription. A veterinary prescription is required for all other scheduled substances. Stock Remedies are also OTC products.

Adversedrug reactionsareaddressed in both Acts. It is obligatory for Registration Holders to forward to the registrar re ports of suspected adverse reactions to products registered under Act 36/47 that cometo their attention. Theregulations of Act 101/65 pertaining to adverse drug reactions (Regulation 12 (3) (a) to (j)) are currently being reviewed.

The purpose of this paper is to present the suspected adverse reactions reported to the Veterinary Pharmacovigilance Centre during the period January 1998 February 2001 for the interest and education of members of the veterinary profession. It is hoped that this will create an awareness of the importance of monitoring adverse reactions and stimulate reporting by veterinarians.

\section{MATERIALS AND METHODS}

The Veterinary Pharmacovigilance Centre relies on spontaneous reports of suspected adverse drug reactions. Reporting is voluntary and reports might be received from veterinarians, paraveterinary professionals, pharmacists, the general public or pharmaceutical companies. Reporters are requested to complete and submit a form (Appendix A), which is published in the Index of Veterinary Specialities (MIMS). Report forms can also be faxed or e-mailed on request and are available on the website of the South African Veterinary Association.

Upon receipt, each report is marked with the date and given a sequential number. The minimum information required to appear in each report is: an identifiable source (name and contact details of reporter), an identifiableanimal (species, sex, age), a suspected product (name and/or registration number) and reaction details. If some of this information does not appear on the report, the
Table 1: Number of reports classified according to registration $(n=59)$.

\begin{tabular}{lcc}
\hline Product registration & Number of reports & Percentage \\
\hline Stock Remedies (Act 36) & 34 & $58 \%$ \\
Veterinary Medicines (Act 101) & 21 & $35 \%$ \\
Products not used according to their & 4 & $7 \%$ \\
registration (extra-label use) (Act 101) & & \\
\hline
\end{tabular}

reporter is contacted and requested to submit these details.

Reports that contain all of the abovementioned information arevalidated and entered into a computerised database. Thereafter, the report is presented at the next meeting of the Veterinary Pharmacovigilance Working Group. At these meetings, which are held weekly, each report that was received during the preceding week is evaluated and assigned a causality classification namely:

Certain: There is a plausible time relationship between the administration of the drug and the adverse event, which cannot be explained by a concurrent disease or other drugs or chemicals. The response to withdrawal of the drug (dechallenge) is clinically plausible and the event is definitive pharmacologically or phenomenologically, using a satisfactory rechallenge procedure if necessary.

Probable: There is a plausible time relationship between the administration of the drug and the adverse event, unlikely to be attributed to concurrent disease or other drugs or chemicals, and which follows a clinically reasonable response on withdrawal. A positive rechallenge is not required to fulfil this definition.

Possible: There is a plausible time relationship between the administration of the drug and the adverse event, but the event could also be explained by concurrent disease or other drugs or chemicals. Information on drug withdrawal may be lacking or unclear.

Unlikely: An adverse event with a temporal relationship to drug administration that would make a causal relationship improbable, and in which other drugs, chemicals or underlying disease provide plausible explanation.

Reports are then forwarded to the rele- vant regulatory authority together with an evaluation and recommendation. The Registration Holder (pharmaceutical company) is also informed of any report of a suspected adverse reaction to one of their products.

\section{RESULTS AND DISCUSSION}

In total, 59 reports of suspected adverse drug reactions were received during the period January 1998 to February 2001. Only 8 reports were received during the first 2 years (January 1998 to December 1999). Thereafter, the number of reports increased significantly and 27 reports were received during the year 2000 . The trend of increasing numbers of reports appeared to be continuing as 24 reports had al ready been received by the end of February 2001.

Pharmaceutical companies submitted slightly more than half of the reports (33 reports). The other reports were received from private practitioners and veterinary specialists throughout South Africa.

In Table 1 the reports received by the Veterinary Pharmacovigilance Centre are classified according to the Act under which they are registered.

Most reportswere received for products registered under Act 36 of 1947. More than half of these reports (62\%) stated that non-veterinarians had administered the products.

The Department of Agriculture forwarded all reports of suspected adverse drug reactions to Stock Remedies that came to their attention to the Veterinary Pharmacovigilance Centre. This was not done for Veterinary Medicines.

In Table 2, the reports are classified according to the species in which the adverse drug reaction was observed.

Two reports did not state in which
Table 2: Reports (January 1998 - February 2001) classified according to species $(n=57)$.

\begin{tabular}{lcc}
\hline Species & Number of reports & Percentage (\%) \\
\hline Canine & 19 & 33 \\
Feline & 15 & 26 \\
Bovine & 7 & 12 \\
Ovine/caprine & 6 & 11 \\
Poultry & 4 & 7 \\
Porcine & 3 & 5 \\
Equine & 2 & 4 \\
Giraffe & 1 & 2 \\
\hline
\end{tabular}




\begin{tabular}{|c|c|c|c|c|c|c|}
\hline \multirow[b]{2}{*}{ Active ingredient } & \multirow[b]{2}{*}{ No. of reports } & \multicolumn{5}{|c|}{ Causality classification } \\
\hline & & Certain & Probable & Possible & Unlikely & Unclassifiable \\
\hline Permethrin & 4 & 0 & 2 & 1 & 0 & 1 \\
\hline Diminazene & 4 & 1 & 3 & 0 & 0 & 0 \\
\hline Potentiated sulphonamide & 3 & 0 & 0 & 1 & 2 & 0 \\
\hline Imidocarb & 2 & 1 & 0 & 1 & 0 & 0 \\
\hline Doxycycline & 1 & 0 & 0 & 1 & 0 & 0 \\
\hline Inactivated rabies vaccine & 1 & 0 & 0 & 1 & 0 & 0 \\
\hline Modified live multivalent vaccine & 1 & 0 & 0 & 1 & 0 & 0 \\
\hline Acepromazine & 1 & 0 & 1 & 0 & 0 & 0 \\
\hline Phenylpropanolamine & 1 & 1 & 0 & 0 & 0 & 0 \\
\hline Praziquantel/fenbendazole & 1 & 0 & 0 & 0 & 1 & 0 \\
\hline
\end{tabular}

speciestheadversereaction occurred and could therefore not be further evaluated.

Most of the reports involved small companion animals (i.e. dogs and cats). This was followed by cattle, sheep and goats. Very few reports were received of suspected adverse drug reactions in horses.

Reports received during the period January 1998 to February 2001 have been grouped according to the species involved.

\section{Canine}

Nineteen reports of suspected adverse drug reactions in dogs were received. These reports are summarised in Table 3.

A largeproportion of thereports in dogs (26\%) involved antiprotozoals used for the treatment of babesiosis. Three reports involved owners administering diminazene to their own animals without the supervision of a veterinarian. The symptoms described in these cases could be attributed to diminazene toxicity. In 1 case, the dog died and pathognomonic lesions of diminazene toxicity were found in the central nervous system.

Four reports were received of suspected toxicity after the use of a topical permethrin formulation. The clinical signs described in these reports included vomition, ataxia, muscle tremors and seizures. These could all be attributed to permethrin toxicity.
Two reports were received of dogs that developed hindquarter weakness and/or paralysis after vaccination. In 1 of these reports the symptoms were described after vaccination with an inactivated rabies vaccine. In the other report the dog was vaccinated with a modified live multivalent canine distemper, adenovirus type-2, parainfluenza and parvovirus vaccine. Acute polyradiculoneuritis with ascending paresis and paralysis of the pelvic limbs has been described in a small proportion of individuals after vaccination ${ }^{22}$.

One report was received of circulatory collapse and death in a young dog after administration of acetylpromazine to prevent motion sickness. A relatively high dose was administered $(0.8 \mathrm{mg} / \mathrm{kg})$. As an $\alpha 1$-antagonist, acetylpromazine is known to cause a drop in arterial blood pressure $^{4,5}$. No predisposing conditions of cardiovascular compromise were described in the report.

Onereport was received of seizures in a German Shepherd bitch after treatment with phenylpropanolamine. There is no product containing this active ingredient registered for use in animals in South Africa. However, extra-label use of phenylpropanolamine is widespread among small animal practitioners to treat urinary incontinence in bitches. This $\alpha 1$-adrenergic agonist is used as a nasal decongestant and an anorexiant for weight reduction in humans ${ }^{15}$. Adverse effects of the use of this product in humans include hypertension, anxiety, restlessness and insomnia.

\section{Feline}

Fifteen reports of suspected adverse drug reactions in cats were received. Table 4 summarises these reports.

The largest proportion of reports of suspected adverse drug reactions in cats $(53 \%)$ were after the use of anaesthetic agents.

Six of the 8 reports concerned the use of a steroid anaesthetic formulation containing alphaxalone and alphadalone. Adverse effects included contact dermatitisin thearea prepared for surgery, necrosis of the tongue and other extremities and respiratory embarrassment due to lung oedema. The solubilising agent of this formulation is known to cause histamine release, particularly in dogs but also to a lesser extent in cats. ${ }^{5}$. The abovementioned adverse reactions could be partially attributed to this histamine release, although there may be other mechanisms as well. Warnings of these adverse effects appear on the package insert of this product. One report described muscle spasms and convulsions during the induction of anaesthesia with this product.

Two reports were received of cats that died shortly after induction of anaesthe-

Table 4: Reports in cats, January 1998 to February $2001(n=15)$.

\begin{tabular}{|c|c|c|c|c|c|c|}
\hline \multirow[b]{2}{*}{ Active ingredient } & \multirow[b]{2}{*}{ No. of reports } & \multicolumn{5}{|c|}{ Causality classification } \\
\hline & & Certain & Probable & Possible & Unlikely & Unclassifiable \\
\hline Alphaxalone/alphadalone & 6 & 1 & 3 & 2 & 0 & 0 \\
\hline Ketamine/medetomidine & 2 & 0 & 0 & 2 & 0 & 0 \\
\hline \multicolumn{7}{|l|}{ Streptomycin/neomycin/ } \\
\hline Phthalylsulphathiazole/kaolin/pectin & 2 & 0 & 0 & 1 & 0 & 0 \\
\hline \multicolumn{7}{|c|}{ Chloramphenicol/nystatin/ neomycin/lindane/ } \\
\hline Triamcinelone/Lignocaine & 2 & 1 & 0 & 1 & 0 & 0 \\
\hline Fipronil & 1 & 0 & 1 & 0 & 0 & 0 \\
\hline Theophylline & 1 & 1 & 0 & 0 & 0 & 0 \\
\hline Inactivated multivalent vaccine & 1 & 0 & 0 & 0 & 0 & 1 \\
\hline
\end{tabular}




\begin{tabular}{|c|c|c|c|c|c|c|}
\hline \multirow[b]{2}{*}{ Active ingredient } & \multirow[b]{2}{*}{ No. of reports } & \multicolumn{5}{|c|}{ Causality classification } \\
\hline & & Certain & Probable & Possible & Unlikely & Unclassifiable \\
\hline Deltamethrin & 2 & 0 & 1 & 0 & 1 & 0 \\
\hline Cypermethrin/amitraz & 2 & 0 & 1 & 1 & 0 & 0 \\
\hline Imidocarb & 1 & 0 & 0 & 1 & 0 & 0 \\
\hline Cloprostenol & 1 & 0 & 0 & 1 & 0 & 0 \\
\hline Live calf paratyphoid vaccine & 1 & 1 & 0 & 0 & 0 & 0 \\
\hline
\end{tabular}

sia using a combination of ketamine and medetomidine. In 1 case, the cat was intubated and placed on halothane shortly after induction. It is possible that in this case the synergistic effects of the combined anaesthetic agents resulted in an overdose. Ketamine/medetomidine anaesthesia has been investigated and found to be safe if prolonged with an inhal ant anaesthetic for longer procedures, but at lower concentrations than are normally required ${ }^{3,28}$.

Two reports were received of a suspected adverse reaction to an orallyadministered antidiarrhoeal medicine containing a combination of aminoglycoside and sulphonamide antibiotics, kaolin, pectin and electrolytes. Symptoms described were the formation of vesicles on thetip of thetongue, which progressed to necrosis.

Two reports involved the administration of an aural preparation containing a combination of antimicrobial agents (chloramphenicol, neomycin), an antifungal, and lindane, as well as a corticosteroid and a local anaesthetic used for the treatment of otitis externa and ear mites. In 1 report, the 3rd eyelid of the cat prolapsed immediately after administration of the product. Thereafter, the cat becameataxic, with a head tilt, and salivated and defaecated. This occurred within $0.5 \mathrm{~h}$ of administration and the cat recovered uneventfully after withdrawal of the product. These symptoms of intolerance can be ascribed to the lindane in the formulation and are described on the packageinsert. It iswarned that thisproduct should only be used in cats after a trial touch.

One report was received of irritation and apparent hyperaesthesia after application of a pour-on formulation containing fipronil. These symptoms resolved within a day. The cat had also shown similar symptoms when treated with this product a few months earlier. Skin problems of varying types in dogs and their owners after the use of topical fipronil were also reported to Australia's National Regulatory Authority (NRA) Adverse Experience Reporting Programme in 1997 and 1998. Most of these cases also resolved with minimal medical attention $^{19}$.

A report was received of seizures in a cat treated with theophylline for feline asthma. This cat was concurrently being treated with afluoroquinoloneantimicrobial. Treatment with theophyllinewasinitiated with an intravenous formulation, which was replaced with a sustainedrelease oral formulation after 2 days. Blood concentrations of theophylline were determined approximately $1 \mathrm{~h}$ after the seizure and were found to be 3 times higher than therapeutic levels. Theophylline is a potent stimulant of the central nervous system, and focal and generalised convulsions can occur with high doses $^{21}$. The package insert of the product that was used warns that there are inter-individual variations in the disposition of theophylline and that the dose should be titrated. Ideally, serum theophylline levels should be monitored. The package insert also warns of interactions between theophylline and various drugs if administered concurrently. Among these interactions it is warned that concurrent administration of quinolone derivatives can increase plasma theophylline concentrations.

\section{Bovine}

Seven reports of suspected adverse drug reactions in cattle were received. Table 5 summarises these reports.

Most reports of suspected adverse reac- tionsin cattlefollowed the use of pour-on pyrethroid ectoparasiticides. Two of the reports described dermatitis in cattle following application of these formulations. Another report described hyperaesthesia and irritability in dairy cows shortly after treatment.

One report of suspected inefficacy was received. This report was investigated and it was found that home-made pyrethroid formulations had been used on the farm. Unpublished data suggest that this could lead to the development of resistance to ectoparasiticides.

One report was received of a calf that died acutely from an anaphylactic reaction after administration of a live calf paratyphoid vaccine. The vaccine was administered by the owner without veterinary supervision and had not been stored and handled correctly. Incorrect storage of livevaccines can result in death of bacteria, release of Lipid A and acute anaphylactic reactions.

\section{Ovine/caprine}

Six reports of suspected adverse drug reactions in sheep and goats were re ceived. Table6summarisesthesereports.

Three reports involved acute deaths (within 1-3 minutes) in lambs following the oral administration of a niclosamide anthelmintic formulation. These deaths occurred shortly after the manufacturer had reformulated the product. Post mortem lesions included severe lung oedema and congestion of the viscera, indicative of an anaphylactic reaction.

One report was received of lambs dying of tetanus despite vaccination of ewes before lambing. On investigation, it was found that the farmer had not administered a booster dose in accordance with the instructions on the package insert of the product.

Table 6: Reports in sheep/goats, January 1998 to February $2001(n=6)$.

\begin{tabular}{|c|c|c|c|c|c|c|}
\hline \multirow[b]{2}{*}{ Active ingredient } & \multirow[b]{2}{*}{ No. of reports } & \multicolumn{5}{|c|}{ Causality classification } \\
\hline & & Certain & Probable & Possible & Unlikely & Unclassifiable \\
\hline Niclosamide & 4 & 4 & 0 & 0 & 0 & 0 \\
\hline Albendazole & 1 & 0 & 1 & 0 & 0 & 0 \\
\hline $\begin{array}{l}\text { Inactivated clostridium vaccine/ } \\
\text { moxidectin }\end{array}$ & 1 & 0 & 0 & 0 & 1 & 0 \\
\hline
\end{tabular}




\section{Porcine}

Three reports were received of suspected lack of efficacy of a pentobaribitone formulation used to induce general anaesthesia in 2 boars and a sow. The formulation was not registered for use in this species.

\section{Poultry}

Four reports were received of suspected lack of efficacy of a coccidiosis vaccine used in poultry. Upon investigation, contributory factors such as incorrect handling and administration of the product were identified in all 4 cases.

\section{Equine}

Two reports of suspected adverse drug reactions in horses were received. Both these reports involved the use of an antimicrobial product containing a sulphonamide and trimethoprim.

In 1 report the horse showed signs of excitement and dyspnoea 1-3 min after administration. The horse recovered uneventfully. Anaphylactoid reactions are known to occur in horses after intravenous administration of sulphonamide/trimethoprim combinations and have been attributed to the trimethoprim moiety of these formulations ${ }^{1}$. A warning appears on the package insert that this product should be administered by slow intravenous injection.

In the second report, the horsecollapsed and died after a veterinarian administered the product intravenously. Before administration thehorsehad been sedated with detomidine. A possible interaction may have been the cause of the reaction.

\section{Other species}

One report was received of suspected inefficacy of the opioid etorphine used to immobilise 3 giraffe. The animals were darted but refused to go down. One bull died after an extended chase. The report was not investigated in detail, and other factors that may have contributed to the lack of efficacy could not be excluded.

\section{Limitations of adverse drug reaction monitoring}

The limitations of monitoring spontaneous reports of adverse reactions must be recognised. Under-reporting is a problem encountered worldwide. Spontaneous reporting is also dependent on the ability of veterinarians and paraveterinary professionals to recognise unknown drug-adverseeffectassociations ${ }^{18}$.

Spontaneous reporting does not yield exact information about the frequencies of adverse drug reactions to a particular drug. Accumulated reports of suspected adverse drug reactions could therefore not be used to calculate incidencerates or estimates of drug risk ${ }^{18}$.

Despite these limitations, spontaneous reports serve as a good early warning system of a connection between a drug and an adverse event. These connections are termed 'signals'. Signals then form a basis for the generation of hypotheses, which can be tested by pharmacoepidemiological studies or pharmacological experiments ${ }^{17}$.

\section{CONCLUSIONS AND \\ RECOMMENDATIONS}

The number of reports received by the Veterinary Pharmacovigilance Centre is satisfactory, considering that a formal system of reporting has only existed for a relatively short period. Reports were received of suspected adverse drug reactions in all major species, but certain species were not well represented (e.g. equines). Many different types of adverse reactions were reported, including lack of efficacy, hypersensitivity reactions, misuse of products, known adverse effects and adverse effects associated with the extra-label use of products.

A number of the reports addressed products or situations that are unique to South African conditions, e.g. reportsconcerning the use of antibabesials such as diminazene and imidocarb; reports involving game species unique to Africa; reports concerning the use of ectoparasiticides, which are used extensively owing to the climatic conditions and extensive farming systems in South Africa; reports concerning the use Stock Remedies by animal owners without the supervision of a veterinarian.

The steady increase in the number of reportssubmitted isencouraging. A more formal system of recording and responding to reports is likely to have contributed to the steep rise in the number of reports received in the latter part of 2000 and the beginning of 2001. There also appears to be an increased awareness amongst veterinarians of the importance of adverse reaction monitoring.

Despite the increase in reporting, there remains much room for improvement. Official collaboration and support from both regulatory authorities is currently being sought. Links with local pharmaceutical companies are also being forged. Furthermore, education of the veterinarians, para-veterinary professionals and thegeneral publicmust remain a priority.

\section{ACKNOWLEDGEMENTS}

Theauthor would like to thank Prof. GE Swan, Prof. C G Cotton and Dr D van der Merwe for their help with preparing this manuscript.

\section{REFERENCES}

1. Alexander F, Collett R A 1975 Trimethoprim in the horse. Equine Veterinary Journal 7: 203-206

2. Beechnor J G, Arthur N 1999 Report of suspected adverse drug reactions to veterinary medicinal products: 1998. I rish Veterinary Journal 52: 375-376

3. Becker K, Oechtering G 1996 Die Anästhesie mit Medetomidin und Ketamin bei der Katze. Kleintierpraxis 41: 249-258

4. Boothe N H 1988 Psychotropic agents. In Boothe N H, McDonald L E (eds) Veterinary pharmacology and therapeutics. Iowa State University Press, Ames: 371-395

5. Brander G C, Pugh D M, Bywater R J, Jenkins W L 1991 Veterinary applied pharmacology and therapeutics (5th edn). Ballière Tindall, London, Philadelphia, Toronto, Sydney, Tokyo

6. Canada, Bureau of Veterinary Drugs 1992 Suspected drug adverse reactions reported to the Bureau of Veterinary Drugs. Canadian Veterinary Journal 33: 237-244

7. Canada, Bureau of Veterinary Drugs 1993 Suspected drug adverse reactions reported to theBureau of Veterinary Drugs. Canadian Veterinary Journal 34: 283-286

8. Canada, Bureau of Veterinary Drugs 1995 Suspected drug adverse reactions reported to theBureau of Veterinary Drugs. Canadian Veterinary Journal 36: 246-249

9. Dukes M N G 1990 The importance of adverse reactions in drug regulations. D rug Safety 5: 3-6

10. FDA/CVM 1998 Adverse drug experience reports - a descriptive overview. Available online at http://www.fda.gov/cvm/index/ ade/fdave98.htm

11. Gray A, Evans C, Kidd C 1990 Suspected adverse reactionsto medicinesduring 1989. The Veterinary Record 126: 376-378

12. Gray A 1993 Suspected adverse reaction surveillance scheme 1991: Summary of results. The Veterinary Record 132: 4-6

13. Gray A 1994 Suspected adverse reaction surveillance scheme 1992: summary of results. The Veterinary Record 135: 77-81

14. Gray A 1995 Suspected adverse reactions surveillance scheme for veterinary medicines(SARSS). EquineVeterinary Education 7: 112-114

15. Hardman J G, Limbird L E, Molinoff P B Ruddin R W 1996G oodman and Gilman's The pharmacological basis of therapeutics (9th edn). McGraw Hill, New York

16. Maddison J E 1992 Adverse drug reactions: report of the Australian Veterinary Association Adverse Drug Reaction Subcommittee, 1992. Australian Veterinary Journal 69: 288-291

17. Maddison J E 1994Adverse drug reactions: report of the Australian Veterinary Association Adverse Drug Reaction Subcommittee, 1993. Australian Veterinary Journal 71: 53-56

18. Meyboom R H B 1997 Detecting adverse drug reactions: pharmacovigilance in The Netherlands. Ph.D. thesis, Utrecht University.

19. National Registration Authority $1999 \mathrm{Re}$ port of adverse experiences 1997 and 1998. Available online at http://www.affa.gov. au/nra/

20. Prescott J F, Bagott J D 1993 Antimicrobial therapy in veterinary medicine (2nd edn). Iowa State University Press, Ames.

21. Rall TW 1985 Central nervous system stimulants (the methylxanthines). In Gilman 
A G, Goodman L S, Rall T W, Murad F (eds) Goodman and Gilman's The pharmacological basis of therapeutics (7th edn). Macmillan, New York: 589-603.

22. Schrauwen E, van Ham L 1995 Postvaccinal acute polyradiculoneuritis in a young dog. Progress in Veterinary N eurology 6: 68-70

23. Stephens M D B 1988 The detection of new adverse drug reactions. Macmillan, Basingstoke

24. Swan G E, Sykes R D, Schlebusch J 1994Veterinary drug registration in South Africa: current and future perspectives. Proceed- ings of the 6th International Congress of the European Association for Veterinary Pharmacology and Toxicology Edinburgh, UK 7-11August 1994: 69-70

25. Swan G E, Sykes R D, Schlebusch J 1997 Veterinary drug registration and control in South Africa: current and future perspectives. Proceedings of the southern and eastern African veterinary drug regulatory affairs conference Pretoria, South Africa, 17-20 November 1997: 35-37

26. Swan G E, Sykes R D, Pienaar A C E 1999 Pharmacovigilance. First conference on the
International $\mathrm{H}$ armonisation of Veterinary M edicinal Products Brussels, Belgium, 16-18 November 1999: 23-25

27. Tjälve H 1997 Adverse reactions to veterinary drugs reported in Sweden during 1991-1995. Journal of Veterinary Pharmacology and Therapeutics 20: 105-110

28. Verstegen J, Fargetton X, Donnay I, EctorsF 1990 Comparison of the clinical utility of medetomidine/ketamine and xylazine/ ketamine combinations for the ovariectomy of cats. The Veterinary Record 127: 424-426

\section{APPENDIX A}

Veterinary Medicines - Report on Suspected Adverse Reactions

In Confidence

\section{SECTION ONE: REPORTER DETAILS}

Name and address of reporter:

Code:

Tel: (

Name and address of veterinarian involved or, in the case of a human suspected adverse reaction, the doctor involved:

Code:

Qualifications:

SECTION TWO: ANIMAL DETAILS

No. of animals treated:

No. of animals reacting:

No. of deaths:

\begin{tabular}{|l|l|l|l|l|l|l|}
\hline Species & Breed & Sex (M/F) & Age & Weight & Pregnant (Y/N) & Neutered (Y/N) \\
\hline & & & & & & \\
\hline & & & & & & \\
\hline
\end{tabular}

\section{SECTION THREE: MEDICINE DETAILS}

Please list all veterinary medicines, stock remedies and vaccines administered. Indicate the product suspected of causing the adverse effect by writing '(s)' next to the Trade Name.

\begin{tabular}{|l|l|l|l|l|l|l|}
\hline Trade name & Batch No. & $\begin{array}{c}\text { Actual amount } \\
\text { administered }\end{array}$ & Route & Date started & Date stopped & Reason for use \\
\hline & & & & & \\
\hline \\
Veterinarian $\square \quad$ Owner $\square \quad$ Paraveterinary professional $\square \quad$ Other $\square$
\end{tabular}

Product administered by:

Has the product registration holder been informed?

Yes

No

\section{SECTION FOUR : ADVERSE EVENT DETAILS}

Date of onset:

Duration of adverse event: 
If you need to continue on a separate sheet of paper, please attach and tick this box

Are there any results to follow? Yes $\square$

No

\section{SECTION FIVE: ADVERSE EVENT OUTCOME}

\section{Died}

Euthanased

Congenital anomaly

Intervention required to prevent permanent impairment
Recovered

Ongoing

Other
Event reappeared on rechallenge

Yes

No

Treatment given, if any

Rechallenge not done

If yes, please describe sequelae

SECTION SIX: ADVERSE REACTIONS IN HUMANS

\begin{tabular}{|l|l|l|l|l|}
\hline Name/Initials & Sex & Age & Date of reaction & Nature of reaction \\
\hline & & & & \\
\hline & & & & \\
\hline
\end{tabular}

\section{ADVICE ABOUT REPORTING SUSPECTED ADVERSE REACTIONS}

This form should be completed whenever a suspected adverse reaction is observed during the use of a veterinary medicinal product in:

- animals (including birds and fish)

- incidents involving humans

Please complete the form in BLOCK LETTERS and send it to the Department of Pharmacology and Toxicology, Faculty of Veterinary Science, University of Pretoria, Private Bag X04, Onderstepoort, 0110 or fax to (012) 529-8304

For further information write to the above address or telephone (012) 529-8239 or e-mail rgehring@op.up.ac.za.

\section{What to report:}

-Suspected adverse reactions to registered veterinary medicines,

stock remedies andvaccines.

- Suspected adverse reactions to medicines used extra-labelly in animals.

-Suspected adverse reactions to herbal, homeopathic or other alternative remedies.

-Suspected lack of efficacy of a product.

-Suspected lack of efficacy of a vaccine.

-Misuse of products.

\section{Report even if:}

-You are not certain that the product has caused the event.

-You don't have all the details.

Tick box if extra report forms are required
We are particularly interested in:

-Adverse reactions to recently marketed products - Serious reactions and interactions with all products -Adverse reactions that are not clearly reflected in the package insert

\section{Confidentiality:}

-Identities of the reporter, client and patient will remain strictly confidential.

-The report does not constitute an admission that the veterinarian or the product caused or contributed to the event. 